\title{
Improved Cardiac Function After Catheter Ablation in a Patient With Type B Wolff-Parkinson-White Syndrome With an Old Myocardial Infarction
}

\author{
Satoshi Yamanaka, MD; Takeshi Shirayama, MD; Keiji Inoue, MD; \\ Koichi Kawata, MD; Takakazu Yagi, MD; Akihiro Azuma, MD; \\ Daisuke Inoue, MD; Masao Nakagawa, MD
}

\begin{abstract}
A 67-year-old man was admitted to hospital for the treatment of exertional dyspnea. He suffered from congestive heart failure due to an old inferior myocardial infarction with type B Wolff-Parkinson-White syndrome. Asynchronous wall motion caused by pre-excitation through a right-side bypass tract caused his cardiac function to deteriorate. Catheter ablation of the bypass tract increased the ejection fraction, and improved his symptoms, prior to surgical revascularization. (Jpn Circ J 1998; 62: 860-862)
\end{abstract}

Key Words: Catheter ablation; Ejection fraction; Myocardial infarction; Wolff-Parkinson-White syndrome

$\mathbf{P}$ ercutaneous transluminal angioplasty (PTCA) and coronary artery bypass graft surgery $(\mathrm{CABG})$ have been established as the interventional therapies for ischemic heart disease. One pitfall is, however, the fact that these interventions do not promise a better prognosis in the patients whose ejection fraction $(\mathrm{EF})$ is low 1,2 This case report presents a patient who suffered from an inferior myocardial infarction and asynchronous septal motion due to type B Wolff-Parkinson-White (WPW) syndrome, which together caused low cardiac output. Catheter ablation canceled the abnormal wall motion and led to better cardiac function prior to CABG.

\section{Case Report}

A 67-year-old male was admitted to hospital with the chief complaint of worsening exertional dyspnea. He had suffered an inferior myocardial infarction 17 years ago, but with medication his status had remained at NYHA class II. WPW syndrome had been diagnosed and present without any palpitation attacks since his twenties. Coronary risk factors were systolic hypertension $(168 / 80 \mathrm{mmHg})$, hyperlipidemia (total cholesterol $6.51 \mathrm{mmol} / \mathrm{L}$ ), smoking (20 cigarettes/day $\times 50$ years), and type $\mathrm{A}$ behavior. The physical examination revealed bradycardia (heart rate 50 beats/min) and systolic ejection murmur (Levine 2/6) at the cardiac apex.

A surface electrocardiogram (ECG) showed type B WPW syndrome. The direction of the delta wave suggested a posterolateral right-sided bypass tract. Radionuclide perfusion image with $99 \mathrm{~m}$-technetium tetrofosmin revealed a persistent defect at the infero-posterior left ventricular

(Received June 9, 1998; revised manuscript received July 14, 1998; accepted July 15, 1998)

Second Department of Medicine, Kyoto Prefectural University of Medicine, Kyoto, Japan

Mailing address: Takeshi Shirayama, MD, Kyoto Prefectural University of Medicine, Second Department of Medicine, Kawaramachi Hirokoji, Kamigyo-ku, Kyoto 602-8566, Japan wall after exercise. Coronary lesions were found in 3 vessels; $100 \%$ at $\mathrm{AHA} \# 2,75 \%$ at $\# 6,75 \%$ at $\# 9,99 \%$ at $\# 10,100 \%$ at \#12 and $90 \%$ at \#14. Left ventriculography with a right anterior oblique projection revealed the EF was $33 \%$.

Ultrasound study showed hypokinetic motion at the infero-posterior wall, which became thinner and hyperechogenic. The septal wall motion was asynchronous, though the wall thickness was normal, possibly due to early excitation of right ventricular wall. When $400 \mathrm{mg}$ of procainamide was injected, the delta wave in the ECG disappeared and septal wall motion became normal. Fractioning shortening was increased from 16 to $19 \%$.

These data encouraged us to consider catheter ablation as a method to improve cardiac performance. The rationales of ablative therapy were: (1) CABG would become safer when the EF was better; 1,2 and (2) the prognosis of patients with ischemic heart disease can be poorer when procainamide is administered continuously? After informed consent was obtained, catheter ablation was performed at the posterolateral wall of the right atrium above the tricuspid valve annulus. The shortest atrioventricular and ventriculoatrial conduction times were referenced. Fig 1 shows the ECG during the successful ablation procedure. Thermodilution study showed that the average cardiac output was increased from $3.57 \mathrm{~L} / \mathrm{min}$ (stroke volume, 77.6 $\mathrm{ml}$ ) to $4.98 \mathrm{~L} / \mathrm{min}$ (stroke volume, $85.9 \mathrm{ml}$ ) after the ablation. Septal asynchrony disappeared, as is shown in Figs 2 and 3. The EF increased up to $41 \%$. The patient did not have exertional dyspnea after ablation. Coronary arteries were successfully bypassed with saphenous veins, which were anastomosed sequentially from the aorta to \#4PL+ \#4PD, and from the aorta to \#14+\#9, though the EF did not change after $\mathrm{CABG}$.

\section{Discussion}

Patients with manifest WPW syndrome have asynchronous ventricular wall motion because of abnormal impulse 


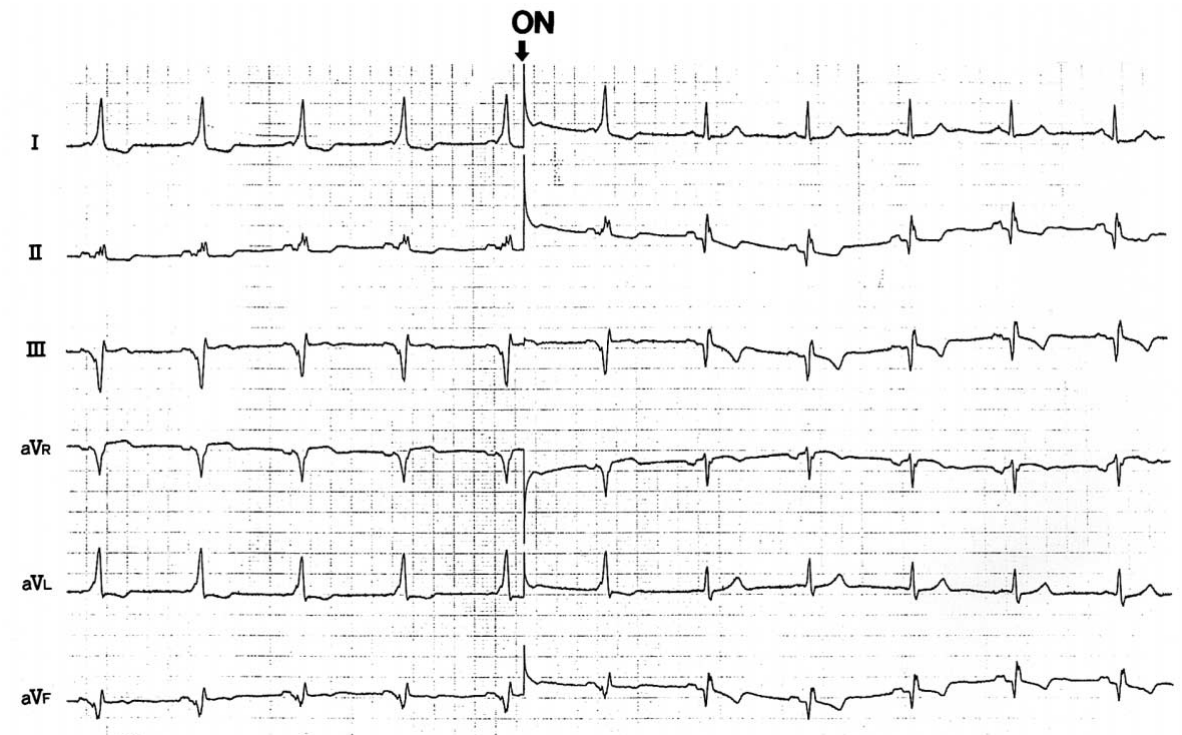

Fig 1. Surface ECG during the successful ablation procedure. 'On' indicates the point where radiofrequency current was applied. After 2 beats, the delta wave disappeared, and abnormal Q wave in leads II, III and $\mathrm{aVF}$ appeared.

\section{pre-ablation}

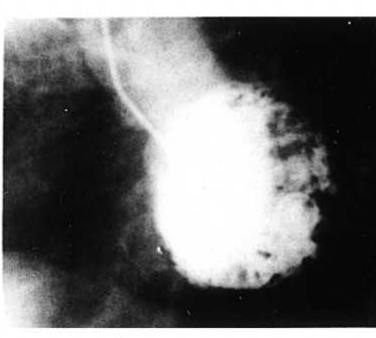

end-diastole

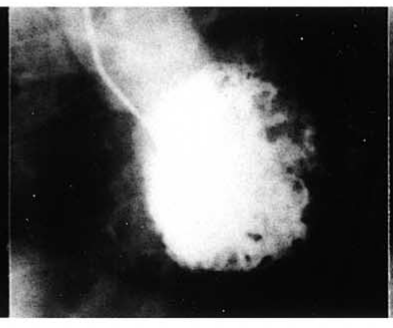

$0.1 \mathrm{sec}$

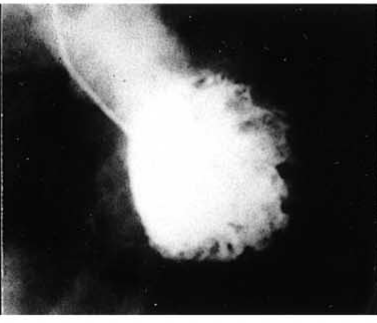

$0.27 \mathrm{sec}$

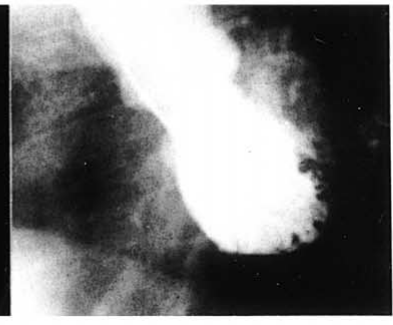

end-systole

\section{post-ablation}

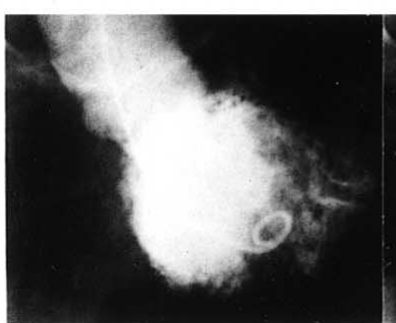

end-diastole

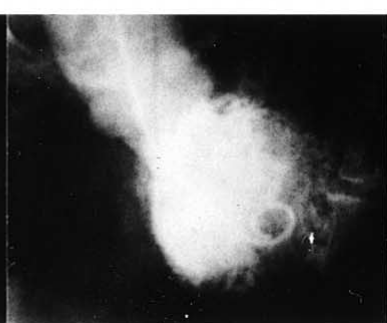

$0.1 \mathrm{sec}$

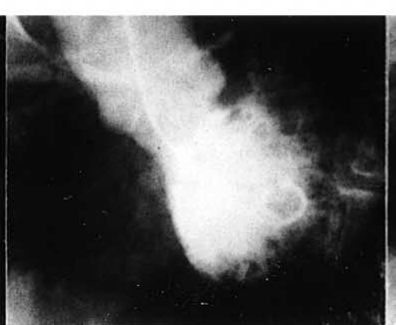

$0.27 \mathrm{sec}$

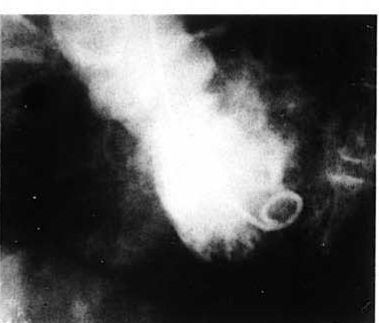

end-systole

Fig 2. Temporal profile of left ventriculography before and after ablation. The left anterior oblique view was compared before and after ablation at end-diastole, $0.1 \mathrm{sec}$ later, $0.27 \mathrm{sec}$ later, and at end-systole. The upper panel (pre-ablation) shows that the upper portion of ventricular septum started to contrast earlier than the lower septum, which appeared to be bulging out slightly. This asynchronous motion is not observed in the lower panel (post-ablation).

propagation through a bypass tract to the ventricle. This abnormality is especially apparent in cases of right-sided bypass tract as well as in the patients who have left bundle branch block4.5 In most of the patients with WPW syndrome, the asynchronous ventricular motion would not cause any symptoms because global cardiac function is kept normal. Nevertheless, the reduction of cardiac output caused by asynchronous motion could be a factor in aggravating concomitant heart failure.

We performed both catheter ablation and surgical re- vascularization, which would be the most controversial issue. In conventional wisdom, re-vascularization to restore cardiac function should have priority for the treatment of ischemic heart disease, and catheter ablation would not be necessary in a case without any recent palpitation attacks. In this particular patient, however, it was less possible to increase the EF by CABG, because the infero-posterior wall was not considered to be viable whereas perfusion to antero-septal wall was so preserved as not to cause deterioration of its motion. In other words, re-perfusion of the 


\section{pre-ablation}
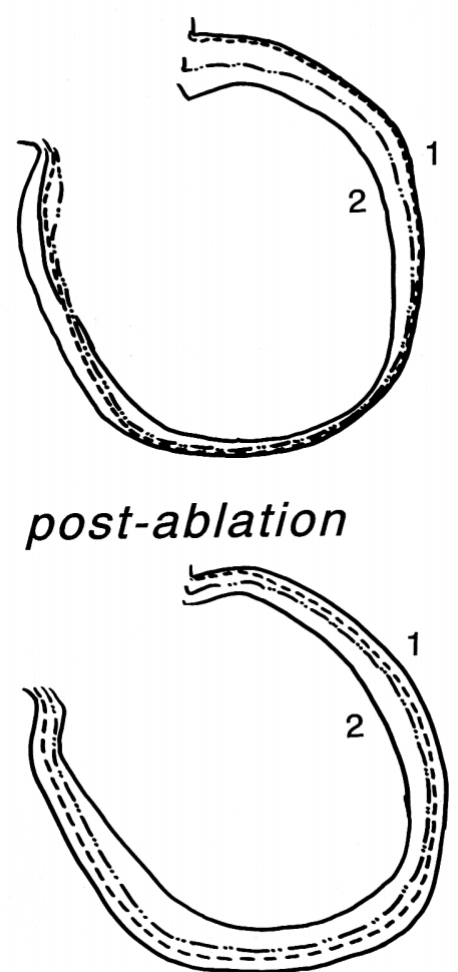

Fig 3. Traces of left ventriculography before and after ablation. Traces are obtained from the left ventriculography shown in Fig 2. Lines 1 and 2 indicate end-diastole and end-systole, respectively. Broken lines show the traces obtained at $0.1 \mathrm{sec}$, and $0.27 \mathrm{sec}$ after end-diastole. Septal asynchronous motion disappeared after catheter ablation. infero-posterior region would have little effect, if any, to recover wall motion and re-perfusion of the antero-septal wall would have little chance of increasing its motion. Although CABG was necessary to salvage the myocardium at risk of coronary insufficiency, only catheter ablation could cancel the antero-septal asynchronous motion caused by pre-excitation, and had a better chance of increasing the EF. Catheter ablation was performed prior to CABG because a better EF would be beneficial for a safer operation.

Our experience indicates that ablation of the bypass tract could improve cardiac function sufficiently enough to relieve symptoms in critical patients with congestive heart failure.

\section{References}

1. Christakis GT, Weisel RD, Fremes SE, Ivanov J, David TE, Goldman BS, et al: Coronary artery bypass grafting in patients with poor ventricular function. J Thorac Cardiovasc Surg 1992; 103: 1083-1092

2. Elefteriades JA, Tolis G Jr, Levi E, Mills LK, Zaret BL: Coronary artery bypass grafting in severe left ventricular dysfunction: Excellent survival with improved ejection fraction and functional state. J Am Coll Cardiol 1993; 22: $1411-1417$

3. Teo KK, Yusuf S: Overview of antiarrhythmic drug trials: implications for antiarrhythmic therapy. In: Singh BN, Dzau VJ, Vanhoutte PM, Woosley RL, editors. Cardiovascular pharmacology and therapeutics. New York: Churchill Livingstone, 1994: 631-643

4. DeMaria AN, Vera Z, Neumann A, Mason DT: Alterations in ventricular contraction pattern in the Wolff-Parkinson-White syndrome: detection by echocardiography. Circulation 1976; 53: $249-257$

5. Hishida H, Sotobata I, Koike, Y, Okumura M, Mizuno Y: Echocardiographic patterns of ventricular contraction in the WolffParkinson-White syndrome. Circulation 1976; 54: 567-570 